\title{
BCYRN1, a c-MYC-activated long non-coding RNA, regulates cell metastasis of non-small-cell lung cancer
}

Tao Hu and Yu-Run Lu*

\begin{abstract}
Background: Long non-coding RNAs (InCRNAs) are increasingly implicated in the regulation of the progression of malignancy.

Aim: To clarify the relations among BCYRN1 (brain cytoplasmic RNA 1, a long non-coding RNA), c-MYC and cell metastasis of non-small-cell lung cancer (NSCLC).

Methods: Real-time PCR was used to measure expression of BCYRN1 in NSCLC. Knockdown and overexpression of C-MYC were respectively performed using shRNA and lentivirus to investigate its effect on BCYRN1 expression. BCYRN1 was respectively knockdown and overexpressed by siRNA and BCYRN1 mimics to investigate its role in regulating cell metastasis in vitro. ChIP (chromatin immunoprecipitation) assay was performed to confirm the binding of C-MYC to the promoter of BCYRN1. Expression levels of matrix metalloproteinases (MMP9 and MMP13) were determined using real-time PCR and Western blotting.

Results: BCYRN1 is upregulated and targeted by C-MYC in NSCLC, leading to the increase of cell motility and invasiveness. RNA interference and lentivirus infection showed a positive correlation between the expressions of C-MYC and BCYRN1. ChIP assay confirmed the binding of C-MYC to the promoter region of BCYRN1 gene. In-vitro cell metastasis experiments demonstrated that BCYRN1 was necessary in the C-MYC-regulated cell migration and invasion. The mRNA and protein expression levels of MMP9 and MMP13 descended with the decreasing BCYRN1 level and ascended with the upregulation of BCYRN1.
\end{abstract}

Conclusion: These findings uncover a regulatory mechanism in NSCLC cells involving the metastasis-promoting InCRNA BCYRN1 that improves expressions of the key metastasis-supporting proteins MMP9 and MMP13.

Keywords: BCYRN1 (brain cytoplasmic RNA 1), IncRNA (long non-coding RNA), c-MYC, Metastasis, NSCLC (non-small-cell lung cancer)

\section{Introduction}

Lung cancer is determined very largely by tobacco smoking, and had the highest incidence in men and the third in women [1]. With a 5 -year overall survival of $10-15 \%$, lung cancer account for more than one-quarter of all cancer deaths, which is the highest mortality $[1,2]$. Nonsmall-cell lung cancer (NSCLC), including adenocarcinoma, squamous cell carcinoma, and large cell carcinoma, composes $80-85 \%$ of lung cancers, and almost half of patients with newly diagnosed NSCLC have metastatic

\footnotetext{
*Correspondence: lu_yurun@163.com
Sichuan Provincial People's Hospital, No. 32, Section 2, 1st Ring Road (West),

* Correspondence: lu_yurun@163.com
Sichuan Provincial People's Hospital, No. 32, Section 2, 1st Ring Road (West), Chengdu City 610072, China
}

disease [3]. It is precisely owing to the high rate of metastasis that NSCLC have become the most lethal human cancer [4].

Long non-coding RNAs (lncRNAs) refer to the noncoding RNAs that were not shorter than $200 \mathrm{nt}$ [5]. It has been found more than once that IncRNA expressions are involved in cancer metastasis [6-8], for example, an lncRNA named MALAT-1 is proved to induce cell migration and tumor metastasis of NSCLC through influencing the expression of motility-related genes $[9,10]$. In accordance to the literature, BCYRN1 (brain cytoplasmic RNA 1) a 200-nucleotide lncRNA, is found highly expressed in some carcinomas of the breast, cervix,

\section{Biomed Central}


oesophagus, lung, ovary, etc., but normally not detectable in the corresponding normal tissues [11].

Studies have indicated its possible role in progression of carcinoma via translational repression of yet to be discovered metastasis suppressors [12,13]. As an oncogene, $c-M Y C$ is closely correlated with metastasis of NSCLC [4], and there is (are) a binding site(s) for c-MYC in BCYRN1 promoter area, based on the online search results (http://www.sabiosciences.com/chipqpcrsearch.php? gene $=$ BCYRN1\&species_id $=0 \&$ factor $=c-M y c \& n i n f o=n \&$ ngene $=$ n\&nfactor $=n$; http://liweilab.genetics.ac.cn/tm/gene . php?st=gn\&gn=c-Myc-binding\%20protein \&gi $=618 \& \mathrm{ti}=$ 9606). During tumor metastasis, extracellular matrix (ECM) interacted with tumor cells in various ways [14]. MMPs (matrix metalloproteinases), a family of more than 20 secreted or transmembrane proteins, have the ability to digest ECM and basement membrane components, which has been shown to have correlations with the metastatic potential of tumor cells [15].

However, the role of BCYRN1, and its correlation with c-MYC and MMPs in metastasis of lung carcinoma are not well understood. The present study was done to preliminarily exposit a possible role of BCYRN1 in regulating cell metastasis of NSCLC.

\section{Materials and methods}

\section{Tissues}

Tumor tissue and the adjacent non-tumor tissue samples were obtained from 20 patients who were diagnosed as NSCLC. The research was performed under the guidance of the institutional ethical guidelines, and the use of human lung tissues was approved by the Medical Ethics Committee of Sichuan Provincial People's Hospital. Every patient involved in the study has signed the written informed consent. The adjacent non-tumor tissue samples were used as controls. All samples were snapfrozen and stored in liquid nitrogen for further use.

\section{Cell lines}

Five human NSCLC cells lines, including A549, H1299, SPCA-1, H520 and L78, and a human normal cell line 16HBE (human bronchial epithelial cells) were purchased from Cell Bank of Type Culture Collection of Chinese Academy of Sciences (Shanghai, China). A549, H1299 and $16 \mathrm{HBE}$ cells were cultured in DMEM medium (90\%) with $10 \%$ fetal bovine serum (Hyclone, USA), and the rest cell lines were cultured in RPMI-1640 medium supplemented with $10 \%$ fetal bovine serum (Hyclone, USA) in a humidified atmosphere of $5 \% \mathrm{CO}_{2}$ at $37^{\circ} \mathrm{C}$.

\section{RNA isolation and real-time polymerase chain reaction (PCR)}

Total RNA was prepared from lung tissues or cells using Trizol reagent (Invitrogen, CA, USA) and cleaned up using RNeasy Mini Kit (Qiagen, Hilden, Germany). BCYRN1 expression level was determined on an ABI $7900 H T$ system using SYBR green qPCR assay (Takara, Dalian, China). Primer sequences were as follows: BCYRN1, forward primer: 5'-CTGGGCAATATAGCGAGAC-3', reverse primer: 5' ${ }^{\prime}$ TGCTTTGAGGGAAG TTACG-3'; c-MYC, forward primer: 5'-TCAAGAGGC GAACACACAAC-3'; reverse primer: 5'-GGCCTTTT CATTGTTTTCCA-3'; GAPDH (used for normalization), forward primer: 5'-ACCACAGTCCATGCCATCAC-3', reverse primer: 5'-TCCACCACCCTGTTGCTGTA-3'. The condition of real-time PCR was $95^{\circ} \mathrm{C}$ for $2 \mathrm{~min}$, followed by 40 cycles of $15 \mathrm{~s}$ at $95^{\circ} \mathrm{C}$ and $1 \mathrm{~min}$ at $55^{\circ} \mathrm{C}$. The data were analyzed using $2^{-\Delta \Delta C t}$ method.

\section{Small interfering RNA (siRNA) and short hairpin RNA (shRNA)}

Control and BCYRN1-specific siRNAs were synthesized by Shanghai GenePharma Co., Ltd (Shanghai, China) and used for transfection into A549 cells according to the manufacturer's protocols. As described by Zhuang et al. [16], lentiviral vector pLKO-1 (Sigma, St Louis, MO, USA) containing $c-M Y C$-specific shRNA (shRNA$c-M Y C)$ was used for the inhibition of c-MYC expression. The $c-M Y C$-targeting sequence was composed of the nucleotides from 1567 to 1585 in the previously reported sequence (GenBank gene accession No. NM_002467.3). The lentiviral vector that contained an irrelevant sequence was used as a negative control. The rest steps were referring to the previous literatures [16-18]. The lentivirus-infected A549 cells were monitored through the observation of green fluorescent protein expression. The knockdown of c-MYC expression in the cells was confirmed by Western blotting.

\section{Overexpression of c-MYC in A549 cells}

A549 cells were infected with lentiviral plasmid pWPXLc-MYC (Addgene, plasmid 36980, Lausanne, Switzerland) using Lipofectamine 2000 (Invitrogen, CA, USA). An empty plasmid pWPXL served as a negative control.

\section{Chromatin immunoprecipitation (ChIP)}

ChIP assay was carried out using an EZ-Magna ChIP kit (Millipore, Billerica, MA, USA) according to the manufacturer's protocol. Briefly, A549 cells $\left(5 \times 10^{6}\right)$ were treated with $1 \%$ formaldehyde for $10 \mathrm{~min}$ for crosslinking, and then quenched by the addition of $0.125 \mathrm{M}$ glycine. The cells were scraped with PBS (phosphate buffer saline) solution and gathered after centrifugation at $800 \mathrm{~g}$ for $5 \mathrm{~min}$ at $4^{\circ} \mathrm{C}$. Then, the cross-linked cells were resuspended in $1 \%$ SDS (sodium dodecyl sulfate) lysis buffer and the soluble chromatin was sheared to fragment DNA of about $400 \mathrm{bp}$ in length by nuclear lysis buffer. The fragmented chromatin 
samples were aliquoted as genomic input DNA or immunoprecipitated with $1 \mathrm{~g}$ c-MYC antibodies or rabbit IgG, incubated at $4^{\circ} \mathrm{C}$ with rotation for $4 \mathrm{~h}$. Immunocomplexes, collected by magnetic separator, were washed and eluted with $1 \% \mathrm{SDS}$ and $0.1 \mathrm{M} \mathrm{NaHCO}_{3}$. DNA was purified on spin columns. The ChIP products and genomic input DNA were quantitatively analyzed by real-time PCR (primer sequences are as follows: forward primer: $5^{\prime}$ ATGTTGCTCAGGGAGGTCTC-3'; reverse primer: 5' GGCTTCTGTCCCTACACCAT-3'). ChIP data were presented as percentage of input normalized to control purifications.

\section{Cell migration and invasion assays}

For the migration assay, referring to the methods described in the report by Jiang et al. [19], $5 \times 10^{4}$ cells were injected into each well of the 24-well transwell chambers with 8.0- $\mu \mathrm{m}$-pore polycarbonate filter inserts (Costar, San Diego, CA, USA). For the invasion assay, $5 \times 10^{4}$ cells were placed into the upper chamber with an insert coated with Matrigel (BD Bioscience, Woburn, MA, USA). Complete media were added to the lower chamber. After incubation for several hours, the cells remaining on the upper membrane were scraped with cotton wool, and the cells that had migrated or invaded to the other side of the membrane were stained with $0.3 \%$ crystal violet. Cell migration or invasion was evaluated by counting whole cell numbers at single filter under an IX71 inverted microscope (Olympus, Tokyo, Japan) at $100 \times$ magnification. All experiments were independently repeated three times.

\section{Western blotting}

After the A549 cells were treated with c-MYC inhibitor 10058-F4, or infected with pWPXL-c-MYC or pWPXL$\mathrm{NC}$, or transfected with siRNA-NC, siRNA-BCYRN1-1 or siRNA-BCYRN1-2, the medium was replaced with serum-free medium. The cells were incubated for another $15 \mathrm{~h}$, following which, the conditioned medium was collected and total proteins from it for c-MYC was electrophoresed on SDS-polyacrylamide gel. C-MYC was then transferred to polyvinylidene fluoride (PVDF) membrane and blocked with nonfat, dry milk and $0.1 \%$ Tween 20 in TBS. The membranes were probed overnight with primary antibodies against c-MYC (Santa Cruz Biotechnology, Santa Cruz, CA). The membranes were then developed with peroxidase-conjugated secondary antibodies (Wuhan Boster Biological Technology, Ltd., Wuhan, China) for $1 \mathrm{~h}$ and enhanced chemiluminescence reagents (Beyotime, Shanghai, China). Protein GAPDH served as a control to equal protein loading.

\section{Enzyme-linked immunoadsorbent assay (ELISA) for MMP9} and MMP13

The concentrations of MMP9 and MMP13 in the supernatant of the media were determined using commercially
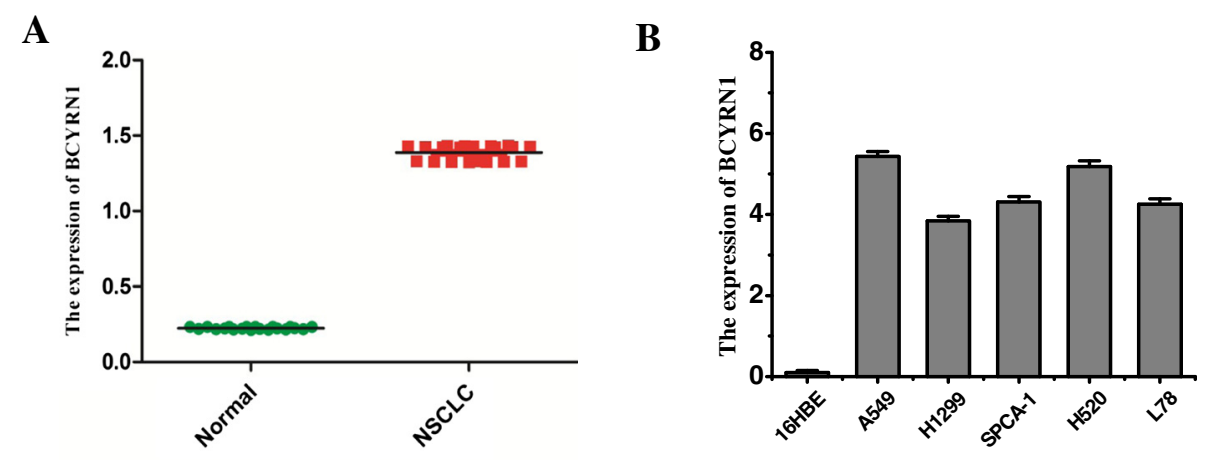

C

D
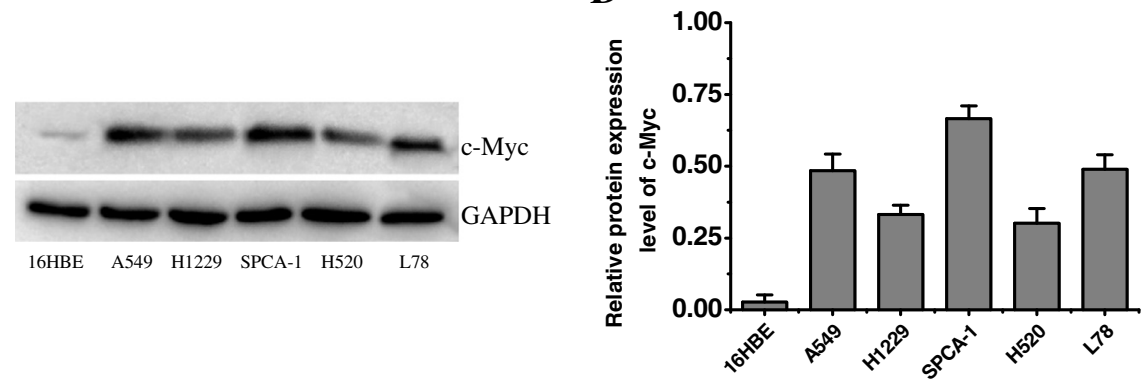

Figure 1 BCYRN1 expression level in NSCLC tissue (A) and cell lines (B), and C-MYC protein level in NSCLC cell lines (C, D). Normal: the adjacent normal tissue, used as a control; 16HBE: a normal human bronchial epithelial cell line. 
available ELISA kits (Invitrogen, CA, USA). The MMP9 and MMP13 present in the samples or standards were bound in wells that had been pre-coated with the antibody. This phase lasted $1 \mathrm{~h}$ for MMP9 and $2 \mathrm{~h}$ for MMP13. A second antibody labeled with peroxidase was added for antigen-antibody immunoreaction in the second incubation phase ( $2 \mathrm{~h}$ for MMP9 and $1 \mathrm{~h}$ for MMP13). The amount of peroxidase that binds to each well was determined by the addition of a pre-prepared medium (tetramethylbenzidene, TMB). The reaction was blocked by adding a $1 \mathrm{M}$ sulfuric acid, and the absorbance of the solution was measured at $450 \mathrm{~nm}$ using a microplate reader (BIO-RAD iMARK 680, Laboratories Inc., Hercules, CA, USA) within $10 \mathrm{~min}$ of the last phase of this experiment. Concentrations of MMP-9 and MMP-13 in the samples were determined by extrapolation from an adapted standard curve. All assays were performed in triplicate [20].

\section{Statistical analysis}

All values were processed with a software DPS v9.50, and expressed as mean \pm standard deviation. Student's $t$ test was used to analyze the difference between groups. The results were considered to be statistically significant, if $p<0.05$.

\section{Results}

Upregulation of BCYRN1 and c-MYC expressions in NSCLC The preliminary experiment demonstrated that the expression of IncRNA BCYRN1 in NSCLC tissue was significantly $(p=0.003, \mathrm{n}=20)$ higher than that in the adjacent normal tissue (Figure 1 A). Likewise, BCYRN1 in each selected NSCLC cell line, including A549, H1299, SPCA-1, H520 and L78, also showed a higher expression level than that in normal human bronchial epithelial cells (16HBE) (Figure $1 \mathrm{~B}$ ). Western blotting analysis indicated that c-MYC level in all of these NSCLC cell lines are significantly higher than that in 16HBE cells (Figure $1 \mathrm{C}, \mathrm{D}$ ).

\section{High expression of BCYRN1 originated from c-MYC's binding to its promoter}

As mentioned above in the Introduction, in the promoter region of BCYRN1, a binding site for c-MYC lies. Therefore, various treatments, including the inhibition

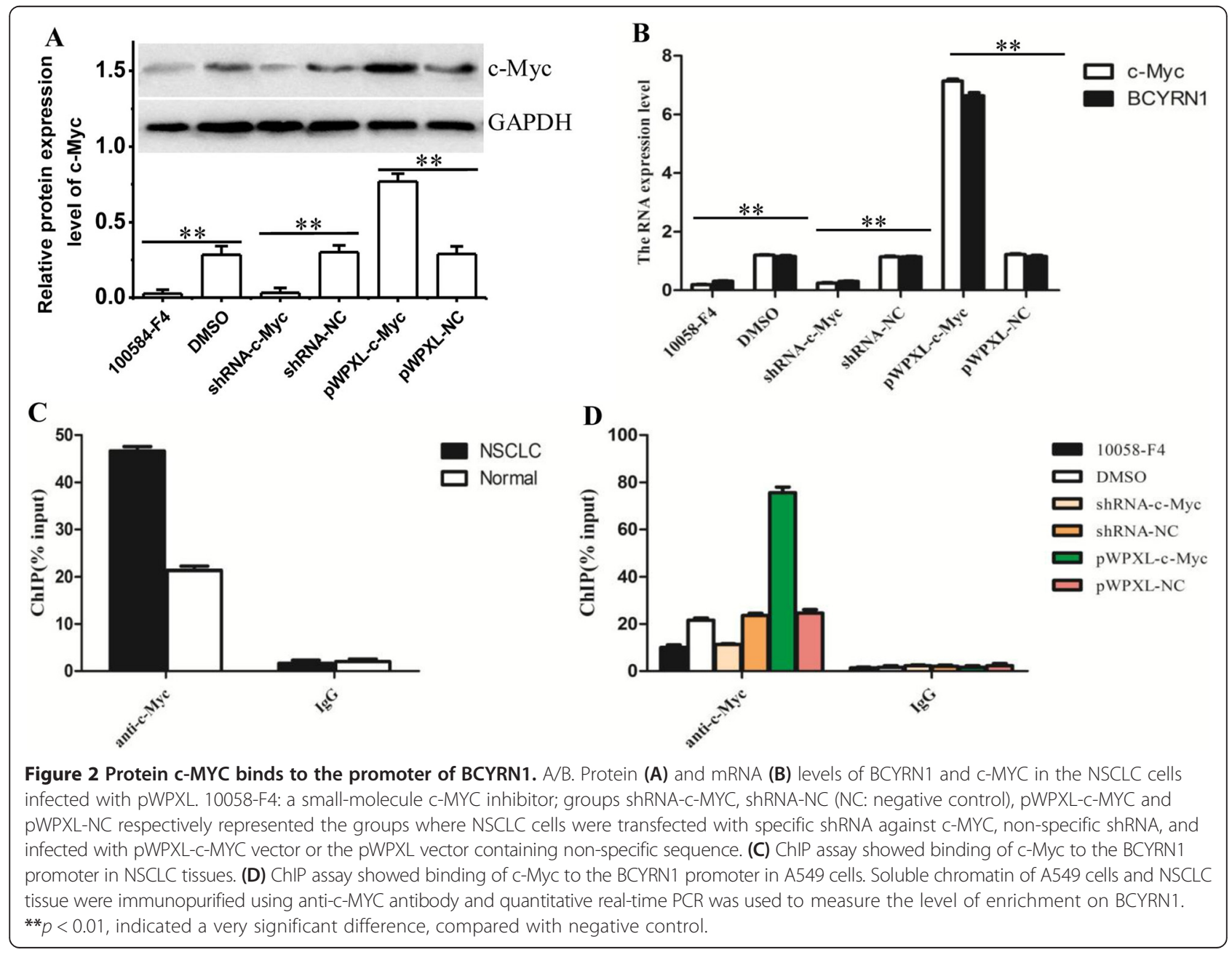


of c-MYC by c-MYC inhibitor or c-MYC knockdown and cMYC overexpression, were used to investigate the relation between BCYRN1 and c-MYC. After the treatment of A549 cells with the small-molecule c-MYC inhibitor 10058-F4, the RNA expressions of $\mathrm{c}-\mathrm{MYC}$ and BCYRN1 both markedly descended $(* * ;<0.01)$, compared with the group only treated with DMSO (dimethylsulfoxide) (Figure $2 \mathrm{~A}, \mathrm{~B})$. When c-MYC was knockdown by its specific shRNA, BCYRN1 expression was also reduced $(* * p<0.01$, shRNA-c-MYC VS shRNA-NC) (Figure 2 A, B). Furthermore, after the A549 cells were infected with pWPXL-c-MYC vector, BCYRN1 overexpressed with the overexpression of $\mathrm{c}-\mathrm{MYC}$, and both of their levels were significantly higher than those in the cells infected with pWPXL-NC $\left.{ }^{* * *} p<0.01\right)$ (Figure $\left.2 \mathrm{~A}, \mathrm{~B}\right)$.

According the results of ChIP assay, the enrichment levels of c-MYC in A549 cells (Figure 2 D) and NSCLC tissues (Figure 2 C) were astonishingly consistent with the above results. These results proved that high expression of BCYRN1 in NSCLC cells originated from c-MYC's binding to the promoter.

\section{Migration and invasion of A549 cells were regulated by c-MYC-activated BCYRN1}

Real-time PCR analysis revealed that the interference efficiency of the siRNA against BCYRN1 at $48 \mathrm{~h}$ after

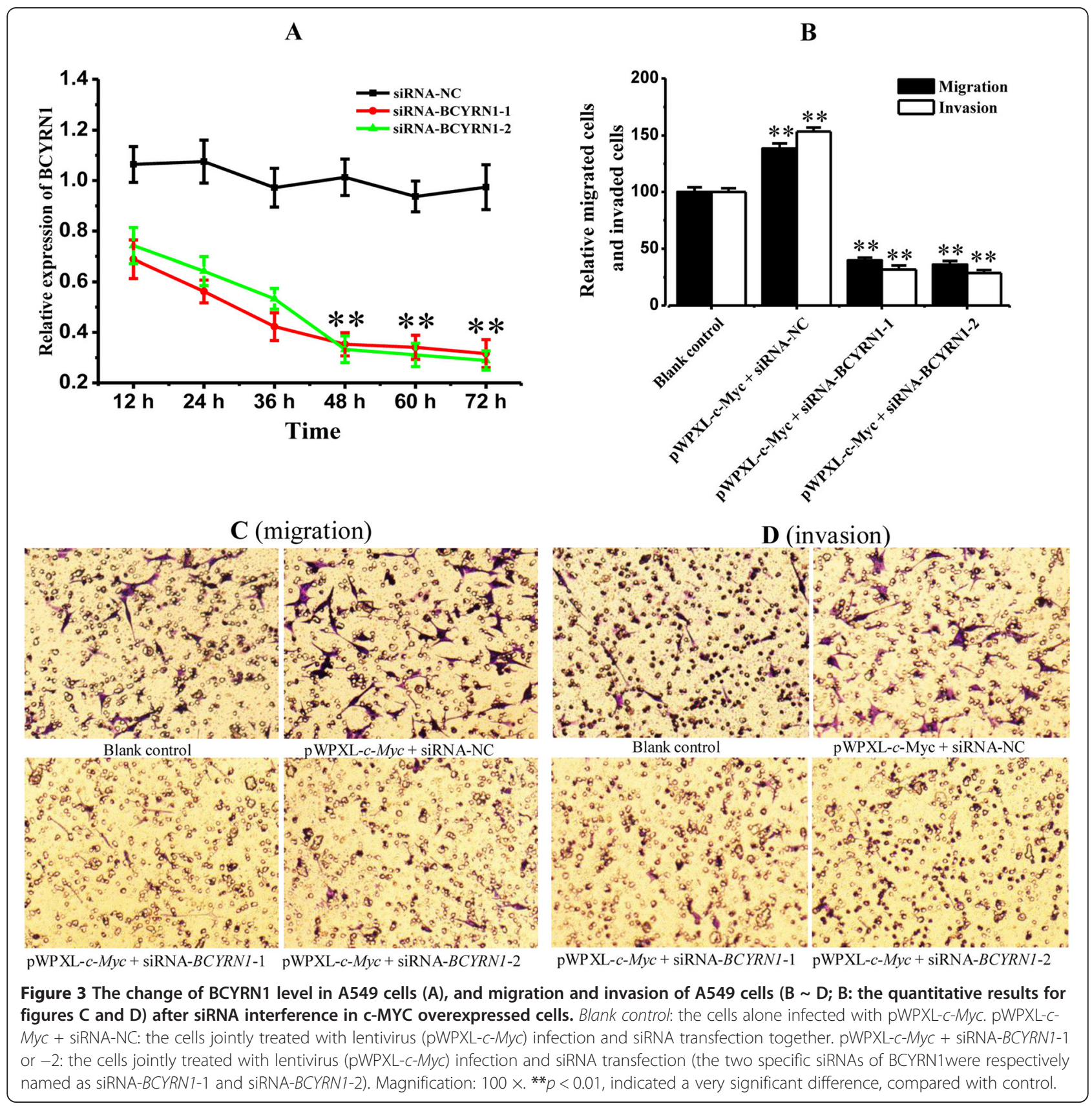


transfection was $65.15 \%$ and $67.13 \%$, respectively (Figure $3 \mathrm{~A})$. As shown in Figure $3(\mathrm{~B} \sim \mathrm{D})$, when treated with pWPXL-c-MYC and siRNA-NC, namely, c-MYCBCYRN1 combination was promoted, both the numbers of migrated cells and invaded cells were significantly larger than those of the untreated cells $(* p<0.01)$. While the A549 cells which were treated with pWPXL-c-MYC and BCYRN1 specific siRNAs simultaneously, meaning the combination of c-MYC and BCYRN1 were downregulated, showed various less migrated and invaded cells than the control ${ }^{* * * *} p<0.01$, Figure $\left.3 \mathrm{~B}\right)$. All of the above results suggested that migration and invasion of A549 cells were regulated by c-MYC-activated BCYRN1.

MMP 9 and MMP 13 were involved in BCYRN1-mediated cell migration and invasion

In the subsequent experiment, the RNA and protein levels of MMP9 and MMP13 in the A549 cells, which were respectively transfected with siRNA-BCYRN1-1 and siRNA-BCYRN1-2, were measured with real-time PCR and ELISA. As shown in Figure 4, the result demonstrated that both RNA and protein levels of MMP9 and MMP13 were significantly downregulated by the siRNAs against BCYRN1 and significantly upregulated by BCYRN1 mimics (compared with negative controls, $* * 0.01$ ), which suggested a positive correlation between BCYRN1 and MMPs.

\section{Discussion}

BCYRN1, also known as BC200, is generally not detected in normal tissue, in addition to the primate nervous system [11]. However, a low but detectable level of BCYRN1 was observed in non-tumor lung tissues in this study. It is very likely that the adjacent non-tumor tissues we obtained were so close to the tumor tissue that the adjacent tissues were not entirely separated from the tumor tissues, which may result in the detectable BCYRN1 level. Despite of this negligible imperfect, the main result agreed with previous reports $[11,13]$. High expressions of BCYRN1 in both NSCLC tissues and cell lines were confirmed by real-time PCR (Figure 1). The aberrant expression of cancer metastasis-associated

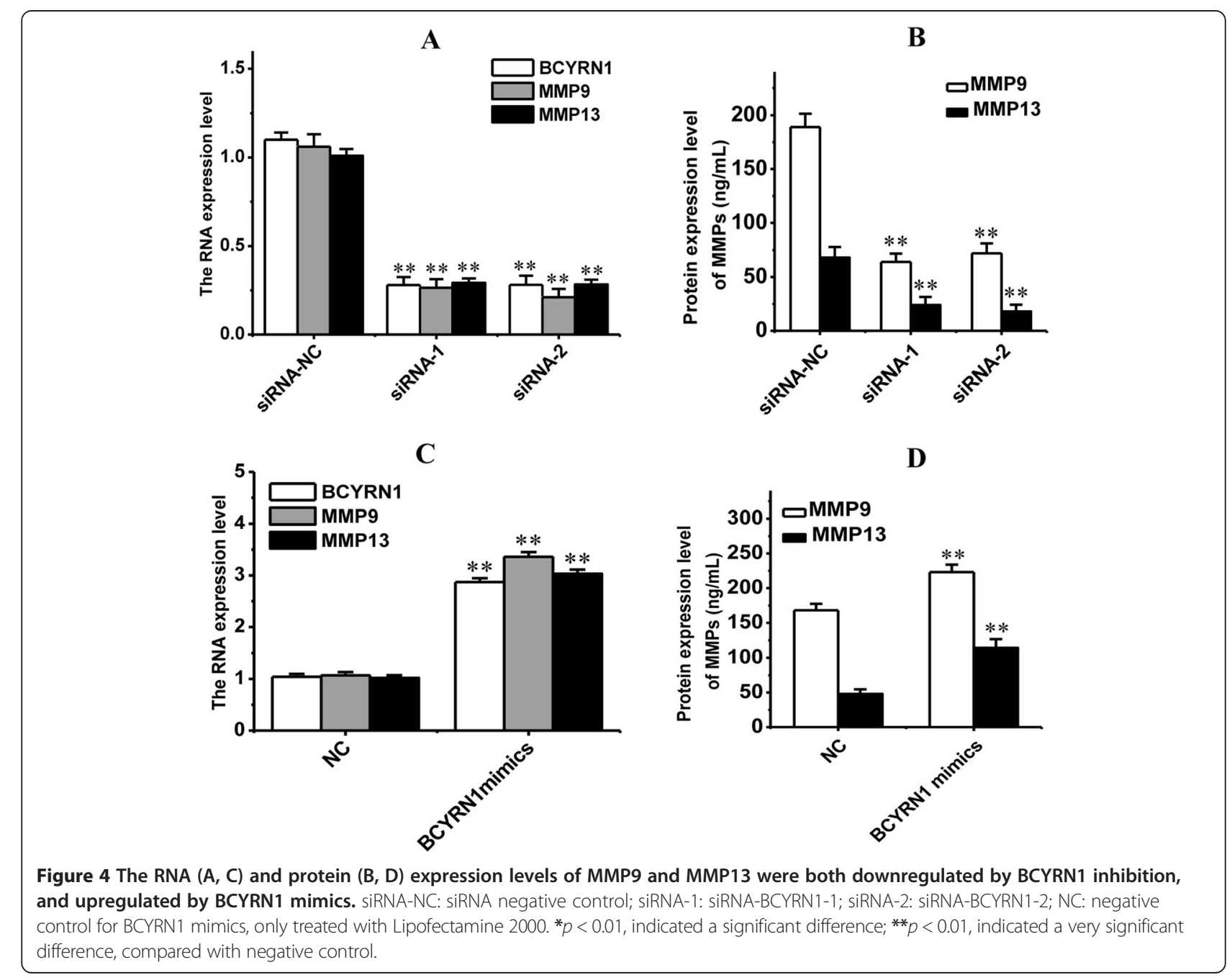


IncRNA may drive tumorigenesis by regulating tumor suppressive and oncogenic pathways [21].

The c-MYC proto-oncogene is a frequently activated oncogene and is estimated to be involved in $20 \%$ of all human cancers, affecting many cancer deaths [22]. CMYC has emerged foremost as a transcription factor, and is generally repressed in tumor suppressive pathways and activated in oncogenic ones, considerable parts of which are often metastasis-related [23,24]. In fact, it is suggested by recent estimates that c-MYC could regulate as many as $15 \%$ of genes in genomes from flies to humans, and its target genes have approached a total of more than 3000 human genes [22]. Based on what we've found online and the result confirmed by ChIP assay, we demonstrated a positive correlation between c-MYC and BCYRN1, indicating the former's binding to the latter (Figure 2) in NSCLC cells. BCYRN1 is therefore a target gene of c-MYC. It is reported that some specific classes of genes that involve cell adhesion were affected by c-MYC, through which c-MYC plays a role in enhancing cell motility [22]. In our present study, the migration and invasion assays showed that BCYRN1 was indispensable in c-MYC-mediated metastasis of A549 cells (Figure 3). It was to say that, as a target gene of cMYC, BCYRN1 mediated migration and invasion of A549 cells through a (some) pathway(s) that is still unknown.

In order to take a step into the mechanism of BCYRN1's regulating tumor cell metastasis, the RNA and protein levels of representative MMPs, namely MMP9 and MMP13, were respectively measured. As a type of ECM-degrading enzymes, activation of MMPs has been proved by various studies to induce migration and invasion of tumor cells [25-27]. MMP9 is most likely involved in the initial degradation of the basement membrane surrounding the tumor, because MMP9 is induced under conditions that require tissue remodeling (including tumor invasion) [28,29]. And MMP13 has a broader substrate specificity than other collagenases and is able to cleave type IV, X and XIV collagens, tenascin, aggrecan core protein and fibronectin [30]. Therefore, the expressed MMP9 and MMP13 are able to regulate the metastasis of cancer cells [31]. In this study, real-time PCR and Western blotting analyses discovered that both RNA and protein levels of the MMP9 and MMP13 decreased with the reducing level of BCYRN1 and increased after treatment with BCYRN1 mimics (Figure 4). So, it was concluded that BCYRN1 somehow influenced the expressions of MMP9 and MMP13, thereby mediating cell migration and invasion in NSCLC.

In conclusion, cell metastasis of NSCLC was regulated by $\mathrm{c}-\mathrm{MYC}$-activated BCYRN1 through promoting the expressions of MMP9 and MMP13.

\section{Competing interests}

The authors declare that they have no competing interests.

\section{Authors' contributions}

TH guaranteed the integrity of the entire study, made substantial contributions to conception and design, participated in the literature research, performed the experimental studies, contributed to data acquisition and manuscript editing.

YRL carried out the data analysis, statistical analysis and the manuscript

preparation. All authors read and approved the final manuscript.

Received: 1 December 2014 Accepted: 16 March 2015

Published online: 01 April 2015

\section{References}

1. Stewart BW, Wild C. World cancer report 2014: World Health Organization. 2014.

2. Siegel R, Ma J, Zou Z, Jemal A. Cancer statistics, 2014. CA Cancer J Clin. 2014;64(1):9-29.

3. Kawabata S, Chiang C-T, Memmott RM, Komiya T, Gills JJ, Dennis PA. Rapamycin decreases expression of thymidylate synthase and enhances the response to pemetrexed in preclinical studies and a Phase I/II clinical study of subjects with non-small cell lung cancer. Cancer Res. 2014;74(19 Supplement):2927.

4. Rapp UR, Korn C, Ceteci F, Karreman C, Luetkenhaus K, Serafin V, et al. MYC is a metastasis gene for non-small-cell lung cancer. PLoS One. 2009;4(6):e6029.

5. Bu D, Yu K, Sun S, Xie C, Skogerbø G, Miao R, et al. NONCODE v3.0: integrative annotation of long noncoding RNAs. Nucleic Acids Research 2012 Jan;40(Database issue):D210-5. doi: 10.1093/nar/gkr1175.

6. Tsai M-C, Spitale RC, Chang HY. Long intergenic noncoding RNAs: new links in cancer progression. Cancer Res. 2011;71(1):3-7.

7. Xu C, Yang M, Tian J, Wang X, Li Z. MALAT-1: a long non-coding RNA and its important 3'end functional motif in colorectal cancer metastasis. Int J Oncol. 2011;39(1):169-75.

8. Gupta RA, Shah N, Wang KC, Kim J, Horlings HM, Wong DJ, et al. Long non-coding RNA HOTAIR reprograms chromatin state to promote cancer metastasis. Nature. 2010;464(7291):1071-6.

9. Schmidt LH, Spieker T, Koschmieder S, Humberg J, Jungen D, Bulk E, et al. The long noncoding MALAT-1 RNA indicates a poor prognosis in non-small cell lung cancer and induces migration and tumor growth. J Thorac Oncol. 2011;6(12):1984-92.

10. Tano K, Mizuno R, Okada T, Rakwal R, Shibato J, Masuo Y, et al. MALAT-1 enhances cell motility of lung adenocarcinoma cells by influencing the expression of motility-related genes. FEBS Lett. 2010;584(22):4575-80.

11. Chen W, Böcker W, Brosius J, Tiedge H. Expression of neural BC200 RNA in human tumours. J Pathol. 1997;183(3):345-51.

12. Redvers RP, Anderson RL. Long Non-Coding RNA: Agent Provocateur in Breast Cancer Metastasis. 2000.

13. lacoangeli A, Lin Y, Morley EJ, Muslimov IA, Bianchi R, Reilly J, et al. BC200 RNA in invasive and preinvasive breast cancer. Carcinogenesis. 2004;25(11):2125-33.

14. Han J-Y, Kim HS, Lee SH, Park WS, Lee JY, Yoo NJ. Immunohistochemical expression of integrins and extracellular matrix proteins in non-small cell lung cancer: correlation with lymph node metastasis. Lung Cancer. 2003:41(1):65-70.

15. Hofmann H-S, Hansen G, Richter G, Taege C, Simm A, Silber R-E, et al. Matrix metalloproteinase-12 expression correlates with local recurrence and metastatic disease in non-small cell lung cancer patients. Clin Cancer Res. 2005;11(3):1086-92.

16. Zhuang D, Mannava S, Grachtchouk V, Tang W, Patil S, Wawrzyniak J, et al. C-MYC overexpression is required for continuous suppression of oncogene-induced senescence in melanoma cells. Oncogene. 2008;27(52):6623-34.

17. Pello OM, De Pizzol M, Mirolo M, Soucek L, Zammataro L, Amabile A, et al. Role of C-MYC in alternative activation of human macrophages and tumor-associated macrophage biology. Blood. 2012;119(2):411-21.

18. Schomber T, Kalberer CP, Wodnar-Filipowicz A, Skoda RC. Gene silencing by lentivirus-mediated delivery of siRNA in human CD34+ cells. Blood. 2004; 103(12):4511-3.

19. Jiang L, Huang Q, Zhang S, Zhang Q, Chang J, Qiu X, et al. Hsa-miR-125a-3p and hsa-miR-125a-5p are downregulated in non-small cell lung cancer and have inverse effects on invasion and migration of lung cancer cells. BMC Cancer. 2010;10(1):318. 
20. Morgia G, Falsaperla M, Malaponte G, Madonia M, Indelicato M, Travali S, et al. Matrix metalloproteinases as diagnostic (MMP-13) and prognostic (MMP-2, MMP-9) markers of prostate cancer. Urol Res. 2005;33(1):44-50.

21. Singla AK, Thirukkumaran C, Dixit R, Wu W. Genomic Landscape of Cancer Metastasis. In: Next Generation Sequencing in Cancer Research. Springer; 2013: 75-90.

22. Dang CV, O'Donnell KA, Zeller KI, Nguyen T, Osthus RC, Li F. The c-Myc target gene network. In: Semin Cancer Biol: 2006: Elsevier; 2006: 253-264.

23. He T-C, Sparks AB, Rago C, Hermeking H, Zawel L, Da Costa LT, et al. Identification of c-MYC as a target of the APC pathway. Science. 1998;281(5382):1509-12.

24. Wang J, Kobayashi T, Floc'h N, Kinkade CW, Aytes A, Dankort D, et al. B-Raf activation cooperates with PTEN loss to drive c-Myc expression in advanced prostate cancer. Cancer Res. 2012;72(18):4765-76.

25. Yu T, Wu Y, Helman Jl, Wen Y, Wang C, Li L. CXCR4 promotes oral squamous cell carcinoma migration and invasion through inducing expression of MMP-9 and MMP-13 via the ERK signaling pathway. Mol Cancer Res. 2011;9(2):161-72.

26. Nabeshima K, Inoue T, Shimao $Y$, Sameshima T. Matrix metalloproteinases in tumor invasion: role for cell migration. Pathol Int. 2002;52(4):255-64.

27. Friedl $P$, Wolf $K$. Tumour-cell invasion and migration: diversity and escape mechanisms. Nat Rev Cancer. 2003;3(5):362-74.

28. Bourguignon LY, Gunja-Smith Z, lida N, Zhu H, Young L, Muller WJ, et al. CD44v $v_{3,8-10}$ Is Involved in Cytoskeleton-Mediated Tumor Cell Migration and Matrix Metalloproteinase (MMP-9) Association in Metastatic Breast Cancer Cells. J Cell Physiol. 1998;176(1):206-15.

29. Polette M, Nawrocki-Raby B, Gilles C, Clavel C, Birembaut P. Tumour invasion and matrix metalloproteinases. Crit Rev Oncol Hematol. 2004:49(3):179-86.

30. Stamenkovic I. Matrix metalloproteinases in tumor invasion and metastasis. In: Seminars in cancer biology: 2000: Elsevier; 2000: 415-433.

31. Ghosh S, Basu M, Roy SS. ETS-1 protein regulates vascular endothelial growth factor-induced matrix metalloproteinase-9 and matrix metalloproteinase-13 expression in human ovarian carcinoma cell line SKOV-3. J Biol Chem. 2012;287(18):15001-15.

\section{Submit your next manuscript to BioMed Central and take full advantage of:}

- Convenient online submission

- Thorough peer review

- No space constraints or color figure charges

- Immediate publication on acceptance

- Inclusion in PubMed, CAS, Scopus and Google Scholar

- Research which is freely available for redistribution 